\title{
To study the Prevalence of obesity among medical students in relation with dietary habits
}

\author{
Swati sonawane ${ }^{1}$, Archana Kadam ${ }^{2 *}$, Hritika Sharma ${ }^{3}$, Tanushri Tetarbe ${ }^{4}$ \\ ${ }^{\mathbf{1 - 2}}$ Associate professor, ${ }^{3-4} \mathrm{UG}$ (MBBS) Students, ${ }^{1}$ Dept of Forensic Medicine and toxicology, ${ }^{2}$ Dept of Physiology, ${ }^{1-4}$ D.Y.Patil Medical \\ College, Navi Mumbai, Maharashtra, India
}

*Corresponding Author: Archana Kadam

Email: drarchanashirsath24@gmail.com

\begin{abstract}
Introduction: Worldwide obesity has nearly tripled since 1975.In 2016, 39\% adults of 18 years and above were overweight and $13 \%$ were obese. Approximately 2.8 million deaths are reported as a result of being overweight or obese. Unhealthy food style, lack of physical activity, and stress are the major factors which contribute to obesity. So this study was done with the aim to estimate the prevalence of obesity among the Medical College students. To access the knowledge about risk factors causing obesity and to take preventive measures to avoid it as they are health educators of community.

Objective: To determine the prevalence of obesity in medical students, to access their knowledge towards risk factors of obesity Material and Methods: A cross-sectional study was conducted among 500 medical students of D.Y.Patil Medical College Navi Mumbai from Jan - June 2019. Consent was obtained from the study participants after explaining the purpose of study. Data was collected using a pre-tested, semi-structured, self administered questionnaire which was validated by department of community Medicine. Anthropometric measurements were taken and body mass index was calculated. Descriptive statistics was used to analyze the data.

Results: The prevalence of overweight and obesity were $36.8 \%$ and $11.1 \%$. Overweight and obesity were more observed in boys $(48.8 \%$, $11.6 \%)$ than girls $(30 \%, 10.55 \%)$..

Conclusions: The prevalence was found to be high among medical college students which were contributed by various risk factors. This can be reduced by modifying their diet, engaging in regular physical activity.
\end{abstract}

Keywords: Obesity, body mass index, Medical students.

\section{Introduction}

Obesity has become a disease of public health concern for both developed and developing countries. Globally, obesity has been estimated to be the fifth leading cause of mortality. ${ }^{1}$ Problem of overweight and obesity has been recognized as public health problem worldwide due to the fact that it increases the risk of chronic diseases such as Cardiovascular Diseases (CVD), stroke, diabetes, sleep apnea, osteoarthritis and many types of cancer. ${ }^{2-5}$

The professional students, including medical students are in a high risk when obesity is concerned. This is mainly because medical education is stressful and factors like social isolation, pressure of examination, discrepancies between expectation and reality all can be anticipated to bring psychological stress. Apart from that due to the very demanding course and time schedules of the medical degree; medical students are known to be involved in less physical activity and more sedentary life style..$^{5}$ World health organization defines overweight and obesity as abnormal and excessive fat accumulation that presents a risk of health. A simple measure used to calculate overweight and obesity in adult is body mass index. Body mass index is defined as body weight in kilogram divided by square of his height in meters $\left(\mathrm{kg} / \mathrm{m}^{2}\right)$.

According World Health organization, 39\% of adults of aged 18 years and above were overweight and 13\% were obese in 2016. Approximately 2.8 million deaths are reported as a result of being overweight or obese. ${ }^{6}$

\section{Objectives}

1. To determine the prevalence of obesity in medical students.
2. To access their knowledge towards risk factors of obesity.

\section{Material and Methods}

A cross-sectional study was conducted among Medical students of age (18-30 yrs) of D.Y. Medical College Nerul Navi Mumbai from Jan-June 2019. Utmost care was taken to maintain privacy and confidentiality. Waiver consent was taken from students who had participated voluntarily in the study. Data was collected from 500 students by using a validated, self-administered questionnaire. It includes information regarding age, sex, dietary habits, frequency of consumption of junk foods, physical activity. Anthropometric measurements such as height, weight, were taken. BMI is the simple index of weight for height which provides the most useful measurement of overweight and obesity as it is the same for both sexes and for all ages of adults. BMI was calculated and graded according to WHO Asia-pacific guidelines, it identifies overweight when BMI is 23-24.9 and obese when BMI is 25 and above ${ }^{-7}$ The data collected was coded and entered in Microsoft Excel and analyzed using SPSS version 17.0 software. Descriptive statistics was used for data analysis and the data was represented in the form of percentages, mean.

\section{Results}

We conducted the study on 500 medical students. Out of them (36\%) 180 males and 320 (64\%) were females. The prevalence of overweight and obesity in medical students was (184) $36.8 \%$ and (55) $11.1 \%$ respectively. 
Table 1: The relationship between diet habits and different BMI categories

\begin{tabular}{|l|c|c|c|c|}
\hline BMI & $\mathbf{1 1 8 . 5}$ & $\mathbf{1 8 . 5}-\mathbf{2 2 . 9}$ Normal & $\mathbf{2 3 - 2 4 . 9}$ Overweight & $>$ 25 Obese \\
\hline Vegetarian & $11.7 \%$ & $43.6 \%$ & $48.9 \%$ & $6.2 \%$ \\
\hline Mixed & $9.6 \%$ & $41.8 \%$ & $36.4 \%$ & $12 \%$ \\
\hline
\end{tabular}

Most of the students who consumed junk food more than 3 times per day were more obese (13\%) than students were taking junk food 1-3 times per week (8\%) and those who were not taking it at all (6\%).

Table 2: The relationship between diet habits and different BMI categories

\begin{tabular}{|c|c|c|c|c|}
\hline Body mass index & $<\mathbf{1 8 . 5}$ & $\mathbf{1 8 . 5}-\mathbf{2 2 . 9}$ Normal & $\mathbf{2 3 - 2 4 . 9}$ Overweight & $>\mathbf{2 5}$ Obese \\
\cline { 1 - 3 } Junk food & & $53 \%$ & $23 \%$ & $6 \%$ \\
\hline No & $19 \%$ & $47 \%$ & $27 \%$ & $8 \%$ \\
\hline 1-3times/wk & $10.9 \%$ & $38 \%$ & $43 \%$ & $13 \%$ \\
\hline
\end{tabular}

In our study it was found $49 \%$ students skipped their meals and $51 \%$ had their regular meals. The students who were tendency to skip their breakfast more obese (18.4\%) than those who skip their lunch (13\%).

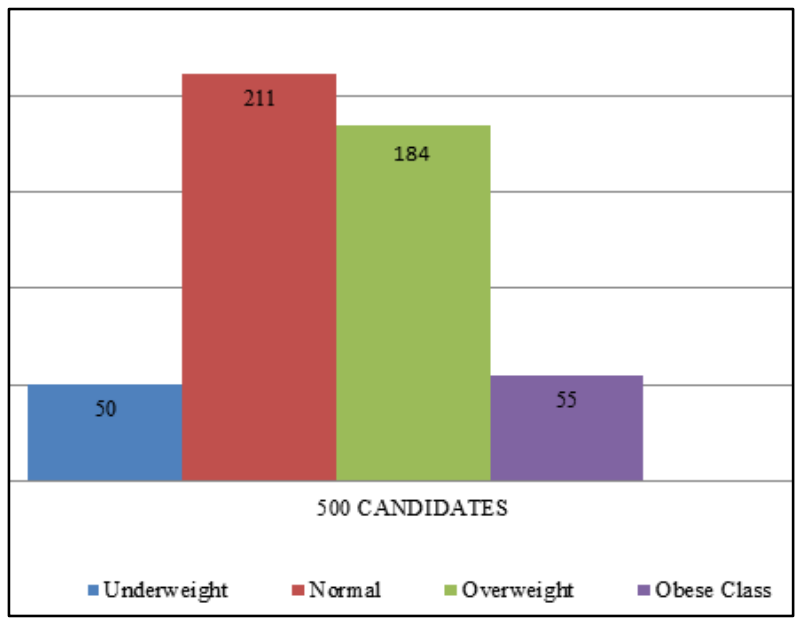

Fig. 1: BMI distribution of the sample

The prevalence of overweight and obesity was higher in males $48.3 \%$ and $11.5 \%$ than in females $30.1 \%$ and $10.6 \%$ respectively.

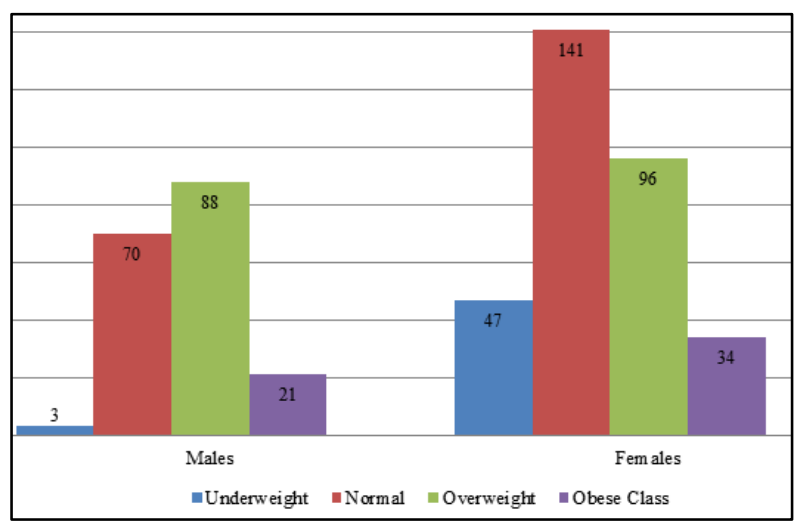

Fig. 2: Gender vise BMI distribution of the sample

Age of the Students in our sample was from 18 to 30 years. The prevalence of obesity was higher in $26-30$ years $(14 \%)$ than in age group $18-21$ years $(9 \%)$.
In our study $81 \%$ students were preferred mixed diet and $19 \%$ were vegetarian. Percentage of obesity $(12 \%)$ was higher in mixed diet than vegetarian diet $(6.2 \%)$.

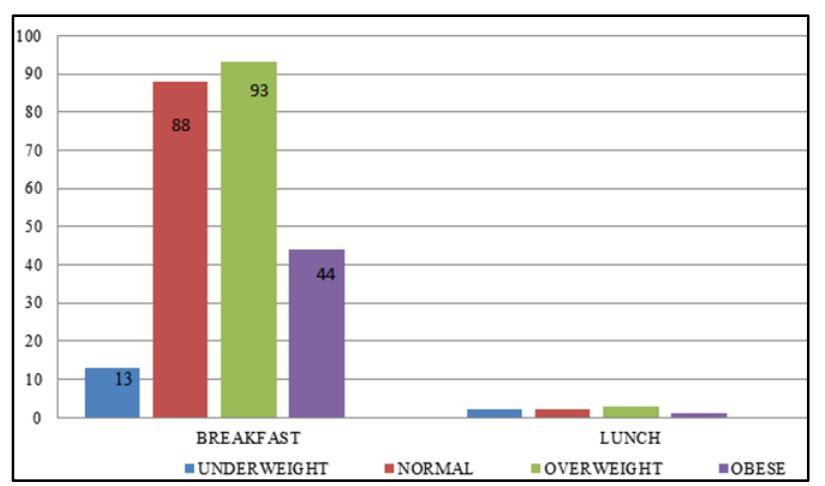

Fig. 3: If yes, which meal do you often skip?

The study provides information regarding the number of meals affect the obesity. The students who had habit of taking more than 4 meals a day were more obese $(33 \%)$ than with students who had 2 meals a day $(7 \%)$.

\section{Discussion}

Obesity in India has reached epidemic proportions in 21st century, with morbid obesity affecting $5 \%$ of the country's population. The prevalence of overweight and obesity in our study was (184) $36.8 \%$ and (55) $11.1 \%$ respectively. Similar prevalence of obesity $11.32 \%$ was observed among the medical students in Bangalore, done by Gudegowdai K S et al in 2018.The findings of study done among medical students by Adhikari et al in Kolkata in 2014 which showed the prevalence of overweight and obese to be $18 \%$ and $2 \%$ which was lower than our study. The study done by Manojan KK et al in Kerala in 2013 showed the prevalence of overweight and obesity to be $24.57 \%$ and $25.71 \% .^{8-10}$ These all studies were based on WHO Asia-Pacific guidelines.

The prevalence of overweight and obesity was higher in males $48.3 \%$ and $11.5 \%$ than in females $30.1 \%$ and $10.6 \%$ 
respectively. Similar findings were reported by Gudegowdai $\mathrm{K} \mathrm{S}$ et al, Adhikari et al and Gupta et al. ${ }^{8-10}$

In this study, we observed that prevalence of obesity in students of aged 26-29 years was $14 \%$ comparatively more than seen among the students aged 18-21 years 9\%. In our study, Percentage of obesity was higher in mixed diet $12 \%$ than vegetarian diet $6.2 \%$. In our study BMI was significantly associated with sex, age, type of diet, skipping meals, frequency of junk food, and number of meals in a day, similar findings were observed in study by Deotale MK et al in Mumbai in 2015. ${ }^{11}$ The junk foods contain more amount of fat than carbohydrate and protein which finally results in obesity or overweight. Diet and lifestyle have a great influence on overweight and obesity. They had adequate knowledge regarding risk factors of obesity but not able to implement healthy eating habits. It may be because of the busy schedule of college hours, less time for lunch/breakfast, emergencies duties which predisposes them to overweight and obesity.

\section{Conclusion}

The prevalence of overweight and obesity was $36.4 \%$ and $11 \%$ among medical students. This is very serious health issue in medical students as they are the future doctors, health leaders to the community. Students have good knowledge about preventive measures to control obesity but lack in adoption of appropriate practices. The study reinforces the need to implement healthy lifestyle, healthy food habits and regular exercise, among medical students to have healthy future.

\section{Source of Funding: None}

Conflict of Interest: None

\section{References}

1. W. P. T. James, R. Jackson-Leach, C. Ni Mhurchu. "Overweight and obesity (high body mass index)",in Comparative Quantification of Health Risks: Global and Regional Burden of Disease Attribution to Selected Major Risk Factors, vol.1,497-596, 2004.

2. Blair SN, Shaten J, Brownell K, Collins G, Lissner L. (1993) Body weight change, all-cause Mortality and cause-specific mortality in the Multiple Risk Factors Intervention Trail. Ann Intern Med 119: 749-57.

3. Must A, Strauss RS. (1999) Risks and consequences of childhood and adolescent obesity. Int J Obes Relat Metab Disord 23: S2-S11.

4. Kenchaiah S, Evans JC, Levy D, Wilson PW, Benjamin EJ, et al. (2002) Obesity and the risk factors of the heart failure. $N$ Engl J Med 347: 305-13.

5. Malnick SD, Knobler H. (2006) The medical complications of obesity. QJM 99:565-79.

6. https://www.who.int/news-room/fact-sheets/detail/obesity-andoverweight accessed on 30th July 2019.

7. https://www.nhp.gov.in/disease/non-communicabledisease/obesity accessed on 31th July 2019.

8. Gudegowda K.S.et al. Prevalence of overweight and obesity among medical college Students, Bangalore. Int J Community Med Public Health. 2018 May; 5(5):1881-1886.

9. Manojan KK, Benny PV, Bindu A. Prevalence of obesity and overweight among medical students based on new Asia-Pacific BMI guideline.Int J Prevent Therap Med. 2014;2(1):1-3.

10. Adhikari A, Dey I, Mandal NK. A Study on Overweight \& Obesity and its Risk Factors among Undergraduate Students of a Medical College in Kolkata. J Comprehensive Health. 2015; 3(2):42-51.

11. Deotale MK et al. Int J Sci Rep. 2015 May; 1(1):74-9.

How to cite this article: Sonawane $\mathrm{S}$, Kadam A, Sharma H,Tetarbe T, To study the Prevalence of obesity among medical students in relation with dietary habits, India $J$ forensic community Med,2019;6(4):211-3. 